\title{
The Wealth Effects of Proactive and Reactive \\ Corporate Name Change Strategies
}

\author{
Nils-Erik Aaby \\ Thomas J. Zwirlein \\ University of Colorado at Colorado Springs \\ Colorado Springs, Colorado \\ Lisa F. Borstadt \\ Northern Arizona University \\ Flagstaff, Arizona
}

\section{Introduction}

Planning and implementing corporate identity programs are important aspects of corporate and marketing strategy. Corporate identity programs embrace everything from the design of corporate names and logos to the very elusive business of image management. A company's image is not only important with respect to present and potential customers, but also to convey the right image to other stakeholders such as employees, stockholders, commercial bankers, investment bankers, rating agencies, the financial press and even government agencies.

One core element of a firm's image and identity is its corporate name. Some practitioners view the corporate name as a "business brand" that must be managed strategically just as product brands. As reported by Rawsthorne [12], a significant consulting industry in the "name and identity management" business, with total 1988 income of $\$ 9.6$ billion, serves firms world-wide. The development of a number of name generation software programs also reflects the importance attached to corporate names.

Expenses associated with developing and changing individual corporate names appear significant. For example, in $1986 \mathrm{UAL}$, Inc., the parent of United Airlines, spent an entire year and $\$ 7.3$ million to produce the new name Allegis. Exxon spent $\$ 200$ million to develop and implement its name change from Esso to Exxon. In spite of substantial amounts spent on changing and creating new names, our knowledge of the importance of corporate names is meager. Many corporate executives question the high fees charged by marketing services organizations for name change development. The purpose of this paper is to examine the merit of such services by assessing the short-term financial consequences of corporate name changes. Given that corporations invest substantial resources to change their corporate name, it is important to know if these investments yield acceptable returns. A corporate name change could be perceived negatively by the investment community due to: 1) the high cost of implementing the name change, or 2) the sacrifice or loss of established name equity. (Name equity refers to the inherent value of a recognizable name including all attributes associated with the name.) Alternatively, a corporate name change might signal a new business strategy and drive by management and be perceived positively by investors. Perceptions regarding corporate name changes should be reflected in stock price movements 
if the announcement of the name change provides new information about the firm. However, if the name change conveys no new information, no share price reaction should be observed.

\section{Review of the Literature}

Many prescriptive efforts related to corporate identity can be found in the literature ([1], [5], [6], [9], [10], [13]). Most of these hail the importance of corporate identity and the importance of having relevant, recognizable, and memorable corporate names. Prior research into the wealth effects of corporate name changes suggests that name changes are of little or no value to shareholders. Howe [7] found no share price reaction to name change announcements. Karpoff and Rankine [8] found a positive 1.9 percent increase in shareholders' wealth over the two days surrounding the public announcement of a name change for a limited sample of 40 firms. Bosch and Hirschey [2] also found that share prices react positively at the time of the public announcement of name changes, however over the 21 day period surrounding the name change, no significant wealth effect was observed. For their total sample of 79 firms, they report a positive and significant share price response over the eleven day period preceding and including the public announcement date, however this is reversed over the ten day period following the name change announcement. Bosch and Hirschey also partitioned their sample into 32 "major" and 47 "minor" corporate name changes similar to our "complete" and "partial" categorization. Their results for "major" and "minor" name changes are the same as for their total sample, i.e., a positive announcement effect that is dissipated over the subsequent ten day period. More recently, Ravichandran, Melicher, and Hearth [11] report positive two-day announcement returns for a sample of 27 "major" (complete) name changes, however no significant differences in risk-adjusted stock performance were found between the one-year pre- and post-name change announcement periods.

The existing evidence suggests that although the public announcement of name changes is met with a positive share price response, the increase in value is not sustained beyond a two-day announcement period horizon. To the contrary, the empirical results of this paper indicate that firms making complete name changes experience a 3.2 percent increase in market value during the 21-day period surrounding the public announcement. Modifications to an existing name however, have no effect on firm value. ${ }^{1}$

1 Prior studies have used much smaller samples. This study contains 151 firms which almost doubles the sample size of the next largest study by Bosch and Hirschey [2], which contained 79 firms. 
Although a 21-day cumulative share price response is not considered to be a long term measure of performance, a 21-day window should be sufficient to capture investors expectations concerning the long-run impact of the name change. ${ }^{2}$ Our evidence is consistent with the view that complete name changes act as a signal of commitment to a new corporate strategy or as a positive net present value investment in a new corporate identity.

\section{Motivation for Corporate Name Changes}

Although corporations change names for a wide variety of reasons, the underlying motivations can be summarized into two overall categories; reactive and proactive. Reactive name changes are the result of events which have already occurred such as corporate restructuring, mergers, acquisitions, or diversification into new products or markets. Although, these events may cause valuation adjustments, the name changes should not, because they are reactive alignments with little strategic value. Name changes made in response to past events should not affect market valuation since no new information is conveyed to the market. In contrast, a substantial number of corporate name changes are made for proactive reasons, i.e., the name change is made in a deliberate attempt to create a new image or corporate identity. This can be viewed as 1) a capital budgeting decision in which an investment is made to generate higher future cash flows to the firm or 2) an information signal, whereby the name change is a means of communicating a new strategy orientation or movement into new and attractive business areas. A name change may be the right medium for communicating such a change if the firm does not wish to divulge their strategic plans to competitors, yet management wants to convey to the market their favorable expectations about future firm performance. If the name change is viewed as a value increasing investment or as a positive information signal, then market values should increase at the announcement of the change.

We categorize name changes into reactive and proactive categories depending on whether the firm completely changed its name or only modified an existing name. Of the 92 partial name changes in our sample, 54 involve dropping a product from the name. Examples of this are Melville Shoe Corp. to Melville Corp., American General Insurance Corp. to American General Corp., Lukens Steel Co. to Lukens Inc., Bic Pen Corp. to Bic Corp., St. Regis Paper Co. to St. Regis Corp. These types of name changes reflect past changes in corporate strategy such as the evolution from single product companies to multi-product companies or to reflect recent diversification into new products or services. The remaining 38 partial name changes can be described

2 Since event study methodology assumes that markets are efficient, any share price response to new information about the firm should reflect the present value of all future cash flows that investors expect as a result of the event. Thus, although we do not measure performance over a long period of time, the 21-day window is sufficiently large to capture the abnormal returns that reflect long-run expectations. 
as follows: 13 involve dropping a name from the name (e.g., Fischbach and Moore Inc. to Fischbach Corp.), 13 involve changing product emphasis (e.g. Peoples Gas Co. to Peoples Energy Co.), and 12 involve some type of restructuring (e.g., M.D.C. Corp. to M.D.C. Holdings Inc.). These partial name changes appear to be reactive in nature, reflecting past strategic actions and therefore, are not likely to convey any new information to the market. Therefore, we hypothesize that partial name changes will have a non-positive effect on equity value.

Alternatively, complete name changes appear to be for proactive reasons. Approximately one-half of the 59 complete name changes involved the creation of a "synthetic" name where word fragments are combined to make new words. Often, "synthetic" names are imagery names designed to convey valuable messages about the benefits of a product, service, or company's business. For example, United Airlines new name, Allegis, was derived from "allegiance" (loyal) and "aegis" (protection). The name was designed to convey the concept of longevity. In some cases synthetic names are nonsense names which combine suffixes, prefixes, and other word fragments into new words with no ostensible meaning (e.g., Acura). While nonsense names, by themselves, don't communicate any valuable message about the company, they are more likely designed to be short, catchy, and easily recognizable. Amoco, Citgo, and Exxon are examples of this type of synthetic name. In our judgement, the underlying motivation for adopting a "synthetic" name, whether a nonsense or imagery name, is to create a new and different corporate image or identity. Firms that change their names completely not only sacrifice existing name equity, but also are likely to incur heavier advertising expenditures as these firms must publicize their new name. Rational managers would not make these decisions if there were no clearly identified performance benefits associated with these costs. Thus, these firms are more likely to be sending stronger strategic signals than firms that make only minor adjustments to their name. Since complete name changes appear to be made for proactive reasons, we hypothesize that the announcement of complete name changes will increase shareholders' wealth.

\section{Sample}

\section{Methodology}

A sample of firms that changed their name during the 1976-1987 period was identified from two sources; the Wall Street Joumal Index and Moody's Industrial and Bank and Finance Manuals. ${ }^{3}$ Beginning in 1979, the WSJ Index has a section titled "Name Changes". Thus it was possible to identify all firms that had changed names during the 1979-1987 period and for which an announcement was published in the Wall Street Journal. To identify name changes that occurred in the 1976-1978 period, the section in the Moody's Manuals entitled "Additional Companies Formerly Included" was searched. This section lists companies which appeared in previous editions of the

${ }^{3}$ This period was chosen to provide a sufficient sample size and to ensure sufficient data availability from the 1989 CRSP tape. 
Moody's Manual, but had been dropped in the current edition. This list indicates if a company was dropped due to a name change and gives the year of the change. The WSJ Index was then searched for the date of the public announcement of the name changes, as well as for any other announcements occurring within plus or minus 10 days of the name change announcement. Firms whose name change announcements were contaminated by any other news announcements within plus or minus ten days of the name change announcement were eliminated from the sample. Additionally, firms whose name change was associated with a merger were dropped from the sample. Of the remaining firms, only companies whose shares are traded on the New York or American Stock Exchanges were included in the final sample. This restriction enabled us to use the CRSP (Center for Research' in Security Prices, University of Chicago) Daily Returns File to obtain capital market data. This search yielded 151 firms to be considered for analysis. ${ }^{4}$

\section{Measurement and Study Design}

The Market Model Residuals method is used to measure the stock price reaction to public announcements of name changes. This empirical technique is used extensively in the financial economics literature. 5 This methodology measures the "abnormal" stock price reaction to the announcement of a corporate event. Under the assumption that the stock market is "efficient" in processing new information, the abnormal return is a measure of the stock markets revaluation as a result of an unanticipated news announcement.

\footnotetext{
4 The sample of 151 firms over a 12 year period seems small when compared to various business publications that have reported over a thousand name changes every year since 1983. This small sample size relative to the huge number of firms changing names results from the various screening procedures we employed. First, the Wall Street Journal Index only publishes a small fraction of the total name changes made in a given year. For example, in 1986 an article in the Wall Street Journal reported that a record 1,382 firms changed their name, yet in the Wall Street Journal Index section on Name Changes, only 52 firms are listed. Second, use of the CRSP tapes limits the sample to only NYSE and AMEX firms. Third, as reported in the Wall Street Joumal, about half of all name changes are attributable to mergers and acquisitions, and these have not been included in our sample. Finally, because of the well documented announcement effects, many firms whose name change announcements were contaminated by other news announcements within plus or minus 10 days, were eliminated from the final sample.

5 The strengths and weaknesses of this standard event study methodology are discussed thoroughly in two papers by Brown and Wamer ([3], [4]).
} 
The market model relates the companies stock returns over time to the general stock market returns using ordinary least squares regression. The market model is:

$$
\tilde{\mathbf{R}}_{j t}=a_{j}+b_{j} \tilde{R}_{m t}+\tilde{e}_{j t}
$$

where, $a_{j}, b_{j}=$ OLS regression coefficients estimated with daily return data for each firm in the sample for the 150 day trading period ending 20 trading days before the event date, where day $t=0$ is defined as the event date,

$\overline{\mathbf{R}}_{\mathrm{mt}}=$ The contemporaneous rate of return on the equally weighted market portfolio on day $t,(t=-170$ to -21$)$

$\tilde{R}_{j t} \quad=$ the rate of return of security $j$ over day $t,(t=-170$ to -21$)$

$\tilde{\mathrm{e}}_{\mathrm{jt}} \quad=$ residual error term of security $\mathrm{j}$ on day $\mathrm{t}$ (i.i.d. normal with mean zero and constant variance).

Regression parameters obtained from the 150 day estimation period prior to the name change are used to predict the expected return for each security in the sample, or,

$$
E\left(R_{j t} \mid R_{m t}\right)=a_{j}+b_{j} R_{m t}
$$

Abnormal retum (AR) is the difference between the expected (forecasted) return and the actual return for each security $j$ on day $t$ as follows,

$$
A R_{j t}=R_{j t}-E\left(R_{j t} \mid R_{m t}\right) .
$$

The cumulative abnormal retum (CAR) for each security $\mathbf{j}\left(\mathrm{CAR}_{\mathbf{j}}\right)$ is calculated by summing the abnormal returns over the days in the event period under study, or,

$$
C A R_{j}=\sum_{t=1}^{T} A R_{j t}
$$

For a sample of $\mathrm{N}$ securities, the measure of abnormal performance between the two dates is given by the mean cumulative abnormal return,

$$
\overline{C A R}=1 / N \sum_{j=1}^{N} C A R_{j}
$$


In the absence of any abnormal performance, the expected value of the mean cumulative abnormal return is equal to zero. To determine whether or not the mean cumulative abnormal return is significantly different from zero, a Z-statistic is calculated. The abnormal return for each firm is measured in the period surrounding the public announcement of the name change. There are three potential times when information about the name change becomes known to various market participants. Firms must notify the stock exchange two weeks (10 trading days) prior to the name change. The exchange then notifies member firms about the impending name change one week (5 trading days) prior to the name change. Finally, the firm typically makes a public announcement (press release to Wall Street Journal) when they change their name. Accordingly we examine the cumulative abnormal returns over several time periods relative to day $t=0$, defined as the WSJ announcement date: 1 ) a two-day return from day $t=-1$ to day $t=0,2)$ a six-day return from day $t=-5$ to day $t=0,3$ ) an 11 day return surrounding the public announcement from day $=-5$ to day $=+5$ and 4) a 21-day return surrounding the public announcement from day $=-10$ to day $=+10$.

\section{Analysis and Results}

The results of the analysis are presented in Table 1 . For the entire sample of 151 firms the 2-day mean cumulative abnormal return (MCAR) is positive, but not statistically significant at the .10 level. The six-day MCAR is a positive 1.1 percent, marginally significant at the .10 level $(Z=1.67) .^{6}$

Table 1: Mean Cumulative Abnormal Returns (MCAR) (Z-statistics in parentheses)

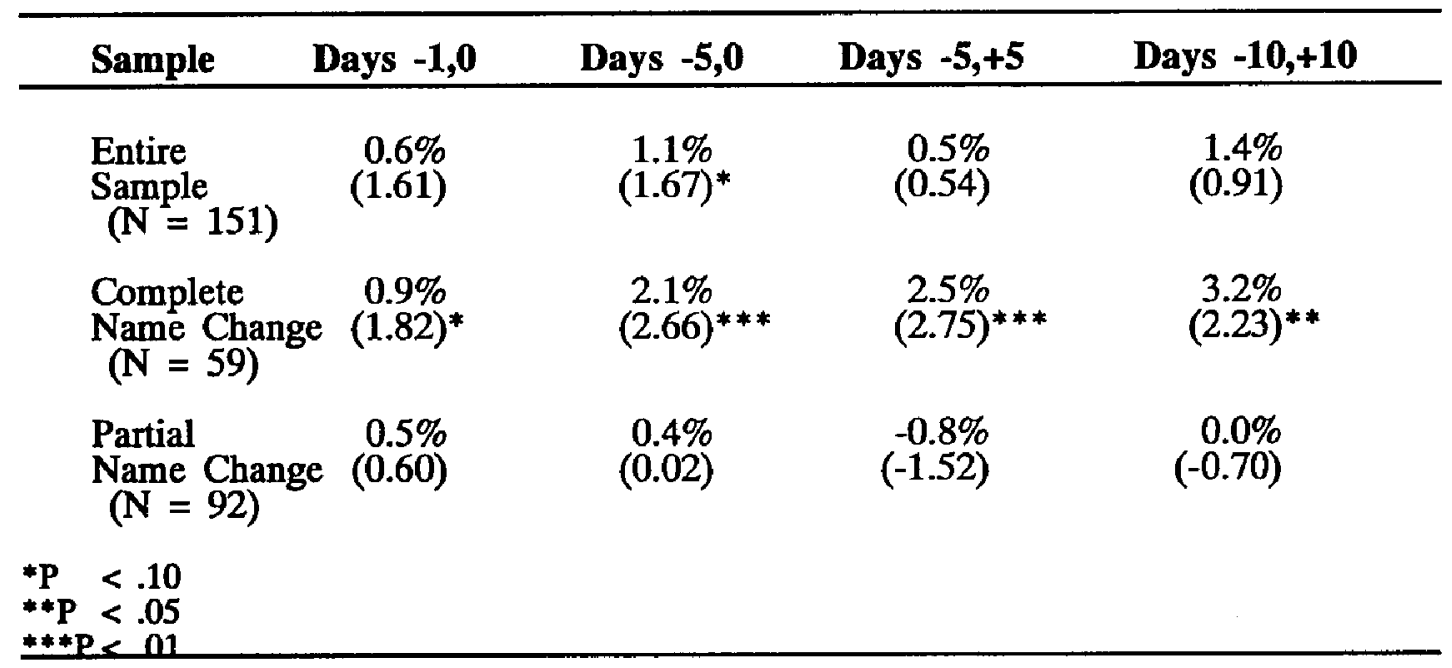

6 The results for the entire sample for the 2-day (not significant) and 6-day (significant) MCARs suggests that the event date (Day $=0$ ) may be misspecified. The information about the name change appears to be capitalized when the exchange notifies member firms rather than when announced in the Wall Street Journal. 
However, when we look at the two time periods surrounding the name change (Days -5 to +5 and Days -10 to +10 ) we find no significant shareholder wealth effects.

When the sample is partitioned into complete and partial name changes the results are more dramatic. For the 59 firms who completely changed their names, the two-day MCAR is 0.9 percent $(\mathrm{Z}=1.82$, statistically significant at the .10 level). The six-day MCAR is a positive 2.1 percent $(Z=2.66$, statistically significant at the .01 level). Moreover, looking at the time periods surrounding the name change announcements, this positive valuation effect does not appear to be transitory. Share prices, on average, increase by 2.5 percent $(Z=2.75)$ over the 11 -day period from Day -5 to Day +5 and by 3.2 percent $(Z=2.23)$ over the 21-day period from Day -10 to Day +10 . This positive market reaction is consistent with investors interpreting complete name changes as a favorable signal of commitment to a new corporate strategy or as a positive net present value investment in a new corporate identity.

In contrast, for the sample of 92 firms who made only minor modifications in their names (partial name changes) we observe no abnormal share price performance upon or surrounding the name change announcement. While a minor modification to a corporate name could also signal a change in strategy, the results indicate that the signal (if any) is very weak. More likely, partial name changes don't provide any new information to the market because they are reactive in nature, reflecting changes in corporate strategy that have already taken place.

Looking at Table 2, the corresponding mean dollar abnormal returns are quite large for the complete name change sample and negligible for the partial name change group. Over the 21-day period surrounding complete name change announcements, firm values increase by $\$ 19.371$ million, on average. In contrast, partial name changes have no effect on firm value over the same 21-day period.

Table 2: Dollar Abnormal Returns (In Millions of Dollars)

\begin{tabular}{lllll}
\hline Sample & Days -1,0 & Days $-\mathbf{5 , 0}$ & Days $-\mathbf{5 , + 5}$ & Days -10,+10 \\
\hline $\begin{array}{l}\text { Entire } \\
\text { Sample } \\
(\mathrm{N}=151)\end{array}$ & $\$ 3.779$ & $\$ 6.928$ & $\$ 3.149$ & $\$ 8.819$ \\
$\begin{array}{l}\text { Complete } \\
\text { Name Changes } \\
(\mathrm{N}=59)\end{array}$ & $\$ 5.448$ & $\$ 12.712$ & $\$ 15.134$ & $\$ 19.371$ \\
$\begin{array}{l}\text { Partial } \\
\text { Name Changes } \\
(\mathrm{N}=92)\end{array}$ & $\$ 3.228$ & $\$ 2.582$ & $-\$ 5.165$ & $\$ 0.000$ \\
\hline
\end{tabular}

*The mean dollar abnormal return is calculated by multiplying the mean market value of equity for a particular sample times the cumulative abnormal return for that sample. 


\section{Conclusions and Implications}

This research examines the strategic motivations and shareholder wealth consequences of corporate name changes made by 151 firms over the period 1976-1987. The empirical results indicate that complete name changes elicit a positive share price reaction, while firms that only modify an existing name experience no change in shareholder wealth. Although the reported results are only valid for a 21-day period surrounding the name change announcement, this window should be sufficient to capture investors long-term expectations regarding the impact of the name change. Our evidence supports the view that corporate name changes can be an effective means of signaling a new strategic emphasis. However, this effect is confined to firms that completely change their names. Complete name changes require large expenditures to change and advertise the new corporate name as well as the loss of existing name equity. Thus, choosing to make a complete name change may reflect commitment by managers to pursue a change in corporate strategy. Alternatively, the positive wealth effects among the complete name change firms, could also be interpreted as a positive net present value investment resulting from a new corporate identity that is expected to generate higher future cash flows to the firm.

\section{References}

1. Ackerman, Lawrence D. "What Makes Successful Service Companies Distinctive?" IABC Communication World, (October 1986), pp. 17-19.

2. Bosch, Jean-Claude and Hirschey, Mark. "The Valuation Effects of Corporate Name Changes." Financial Management, (Winter 1989), pp. 64-72.

3. Brown, Stephen J. and Warner, Jerold B. "Measuring Security Price Information." Joumal of Financial Economics, Vol. 8 (1980), pp. 205-258.

4. Brown, Stephen J. and Warner, Jerold B. "Using Daily Stock Retums: The Case of Event Studies." Journal of Financial Economics, Vol. 14 (1985), pp. 3-31.

5. Dowling, Grahame R. "Managing Your Corporate Images." Industrial Marketing Management, Vol. 15 (1986), pp. 109-115.

6. Gray, Edmund R. and Smeltzer, Larry R. "Planning a Face-Lift: Implementing a Corporate Image Program." Journal of Business Strategy, Vol. 8 (Summer 1987), pp. 4-10.

7. Howe, J. S. "A Rose By Any Other Name: A Note on Corporate Name Changes." Financial Review, (1982), pp. 271-278.

8. Karpoff, J. M. and Rankine, G.W. "The Motives and Wealth Effects of Corporate Name Changes." presented at the 17th Annual Meetings of the Financial Management Association, (October 1987). 
9. Kennedy, Sherril H. "Nurturing Corporate Images." European Journal of Marketing, Vol. 11, (1977), pp. 119-164.

10. Portugal, Joel and Halloran, Keith D. "Avoiding a Corporate Identity Crisis." Management Review, Vol. 75 (April 1986), pp. 43-45.

11. Ravichandran, R, Melicher, R.W., and Hearth, D. "Valuation Effects and Risk-Return Performance Characteristics Associated With Corporate Name Changes." Journal of Financial and Strategic Decisions, forthcoming.

12. Rawsthorne, Alice. "Laying It All on the Line." Financial Times, (March 29, 1989), p. 27.

13. Stancill, James McN. “Upgrade Your Company's Image-Evaluation." Harvard Business Review, (January-February 1984), pp. 16-23. 